\title{
The Intracellular Delivery Of Anti-HPVI6 E7 scFvs Through Engineered Extracellular Vesicles Inhibits The Proliferation Of HPV-Infected Cells
}

This article was published in the following Dove Press journal: International Journal of Nanomedicine

\section{Flavia Ferrantelli $\mathbb{D D}^{1, *}$ Claudia Arenacciol'* Francesco Manfredi ${ }^{\prime}$ Eleonora Olivetta' Chiara Chiozzini (ID) Patrizia Leone' Zulema Percario ${ }^{2}$ Alessandro Ascione Michela Flego' Paola Di Bonito 3 Luisa Accardi $\mathbb{D}^{3}$ Maurizio Federico'}

'National Center for Global Health, Istituto Superiore Di Sanità (ISS), Rome, Italy; ${ }^{2}$ Department of Science, Roma Tre University, Rome, Italy; ${ }^{3}$ Department of Infectious Diseases, Istituto Superiore Di Sanità (ISS), Rome, Italy

*These authors contributed equally to this work
Correspondence: Maurizio Federico National Center for Global Health, Istituto Superiore Di Sanità, Viale Regina Elena, 299, Rome 0016I, Italy

Tel +39-06-4990-3605

$\mathrm{Fax}+39-06-49903210$

Email maurizio.federico@iss.it
Purpose: Single-chain variable fragments ( $\mathrm{scFvs}$ ) are one of the smallest antigen-binding units having the invaluable advantage to be expressed by a unique short open reading frame (ORF). Despite their reduced size, spontaneous cell entry of scFvs remains inefficient, hence precluding the possibility to target intracellular antigens. Here, we describe an original strategy to deliver scFvs inside target cells through engineered extracellular vesicles (EVs). This approach relies on the properties of a Human Immunodeficiency Virus (HIV)-1 Nef mutant protein referred to as Nef ${ }^{\text {mut }}$. It is a previously characterized Nef allele lacking basically all functions of wt Nef, yet strongly accumulating in the EV lumen also when fused at its $\mathrm{C}$-terminus with a foreign protein. To gain the proof-of-principle for the efficacy of the proposed strategy, the tumor-promoting Human Papilloma Virus (HPV)16-E7 protein was considered as a scFv-specific intracellular target. The oncogenic effect of HPV16-E7 relies on its binding to the tumor suppressor $\mathrm{pRb}$ protein leading to a dysregulated cell duplication. Interfering with this interaction means impairing the HPV16-E7induced cell proliferation.

Methods: The Nef ${ }^{\text {mut }}$ gene was fused in frame at its 3 '-terminus with the ORF coding for a previously characterized anti-HPV16-E7 $\mathrm{scFv}$. Interaction between the Nef ${ }^{\text {mut }}$-fused antiHPV16-E7 scFv and the HPV16-E7 protein was tested by both confocal microscope and coimmunoprecipitation analyses on co-transfected cells. The in cis anti-proliferative effect of the Nef ${ }^{\text {mut }}$ /anti-HPV16-E7 scFv was assayed by transfecting HPV16-infected cells. The anti-

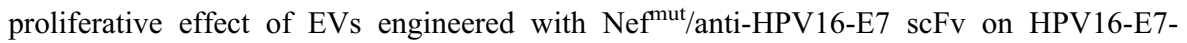
expressing cells was evaluated in two ways: i) through challenge with purified EVs by a Real-Time Cell Analysis system and ii) in transwell co-cultures by an MTS-based assay.

Results: The Nef ${ }^{\text {mut} / a n t i-H P V 16-E 7 ~ s c F v ~ c h i m e r i c ~ p r o d u c t ~ i s ~ e f f i c i e n t l y ~ u p l o a d e d ~ i n ~ E V s, ~ b i n d s ~}$ HPV16-E7, and inhibits the proliferation of HPV16-E7-expressing cells. Most important, challenge with cell-free EVs incorporating the Nef ${ }^{\text {mut }} /$ anti-HPV16-E7 scFv led to the inhibition of proliferation of HPV16-E7-expressing cells. The proliferation of these cells was hindered also when they

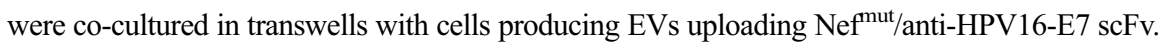

Conclusion: Our data represent the proof-of-concept for the possibility to target intracellular antigens through EV-mediated delivery of scFvs. This finding could be relevant to design novel methods of intracellular therapeutic interventions.

Keywords: single-chain variable fragments, Human Papilloma Virus E7 protein, exosomes, human immunodeficiency virus Nef protein, scFv intracellular delivery

\section{Introduction}

Monoclonal antibodies (mAbs) are largely used in therapy, diagnostics, and biotechnology. However, in view of their large heterotetrameric composition, the 
efficacy of whole $\mathrm{Ab}$ molecules is limited for a number of applications. The complex Ab structure can be reduced in several formats without affecting the binding efficacy. Single-chain variable fragment $(\mathrm{scFv})$ is one of the smallest molecule retaining antigen-binding activity. ${ }^{1,2}$ This molecule consists of $\mathrm{Ab}$ variable regions of both heavy and light chains joined by a peptide linker. Although scFvs have the invaluable advantage of being expressed by a single open reading frame (ORF), their access to intracellular targets is severely impaired by plasma membrane. The most popular way to provide target cells with scFvs relies on the use of gene therapy. In this manner, transduced cells express the specific $\mathrm{scFv}$ (in this case referred to as intrabody), which can bind the intracellular target. ${ }^{3}$ The effects of gene therapy-driven $\mathrm{scFv}$ delivery are operative in actually transduced cells, with little or no benefit for neighboring ones. Our ambition was developing a method to extend the beneficial effects induced by vector-expressed scFvs from the producer to bystander cells. To this aim, we envisioned a strategy relying on in vivo engineering of extracellular vesicles (EVs) through a method we recently described. ${ }^{4}$

EVs comprise a heterogeneous population of membrane vesicles whose size ranges from 50 to $500 \mathrm{~nm}$. They are classified into two major categories: exosomes (50-200 nm) and microvesicles (150-500 nm). ${ }^{5}$ Exosomes originate intracellularly upon inward invagination of endosome membranes $^{6}$ and formation of intraluminal vesicles (ILVs), which then become part of multivesicular bodies (MVBs). They can traffic to either lysosomes for degradation or plasma membrane. In the latter case, MVBs release their contents in the extracellular space upon fusion with plasma membrane. EVs formed by direct budding of plasma membrane are referred to as microvesicles. ${ }^{7}$

We have previously identified a Human Immunodeficiency Virus (HIV)-1 Nef mutant protein (i.e., Nef ${ }^{\mathrm{mut}}$ ) acting as an exosome-anchoring protein. ${ }^{8} \mathrm{Nef}^{\mathrm{mut}}$ is a functionally defective protein mutant lacking the Nef functions typically associated with HIV pathogenesis. ${ }^{9}$ It exhibits extraordinary levels of incorporation into both exosomes and microvesicles, ranging from 50 to 100 fold those of the wild-type isoform. ${ }^{8}$ $\mathrm{Nef}^{\mathrm{mut}}$ can be fused to proteins of choice while retaining its EV-anchoring properties. ${ }^{10-12}$ In this way, $\mathrm{Nef}^{\text {mut }}$ allows incorporation into EVs of large amounts of the products fused to it, which thus remain protected from external neutralization/degradation factors.

In an effort to develop a novel approach to deliver $\mathrm{scFv}$ into target cells, we planned to exploit the strategy based on EV engineering we previously described. ${ }^{4}$ It relies on the intracellular expression of a DNA vector expressing the product of fusion between $\mathrm{Nef}^{\text {mut }}$ and the ORF of choice. This event leads to the release of EVs engineered with the fusion proteins whose entry into target cells allows intracellular delivery of the EV cargo. In the case $\mathrm{Nef}^{\text {mut }}$ is fused with an ORF coding for an $\mathrm{scFv}$, this method has the potential to target and inhibit intracellular antigens in DNA vector expressing cells as well as in bystander ones through the cell-to-cell transfer of scFvengineered EVs.

Here, we demonstrate the possibility to engineer EVs with scFvs and provide experimental evidence supporting the idea that EV-incorporated scFvs can be functional in bystander cells.

\section{Materials And Methods DNA Constructs}

The previously described ORF coding for the anti-HPV16-E7 $43 \mathrm{M} 2 \mathrm{scFv}^{13,14}$ was PCR-amplified using primers including Apa I (forward: 5' GGCCGGGCCCATGGCCGAGGTGC AGCTGGTGG 3') and Acc I (reverse: 5' CCGGGTCTACCT ACTTGTCATCGTCGTCCTTGTAG 3') restriction sites. The PCR product was then inserted in Apa I/Acc I digested pTarget-Nef $^{\text {mut }}$ expression vector ${ }^{10}$ to generate an in frame Nef ${ }^{\text {mut }}-43 \mathrm{M} 2 \mathrm{scFv}$ ORF. The ORF coding for the anti-glucose oxidase from Aspergillus niger ${ }^{15}$ was PCR-amplified from the previously described expression vector using primers including Apa I (forward: 5' ATTGGGCCCGCCATGGCCGAG 3') and $\mathrm{Sal}$ I (reverse: $5^{\prime}$ ATTGTCGACCTACTAATGGTGATG $3^{\prime}$ ) restriction sites, and cloned in Apa I/Sal I restriction sites of pTarget-Nef ${ }^{\text {mut }}$ to generate an in frame $\mathrm{Nef}^{\text {mut }} / \mathrm{GO}$ scFv ORF. All restriction enzymes were from New England Biolabs. A flag tag was inserted at the C-terminus of both $\mathrm{Nef}^{\text {mut }}$-based scFvs. The DNA vector expressing HPV16-E7 fused to the red fluorescent protein was kindly provided by David Pim, ICGEB, Trieste. The pcDNA3 vector expressing a HPV16E7 coded by a nucleotide sequence optimized as previously described $^{16}$ and $6 \times$ His tag flagged at its C-terminus was obtained as a synthesis product from Eurofins. The DNA vectors expressing $\mathrm{Nef}^{\text {mut }}$ and $\mathrm{sg} 25 \mathrm{GFP}$ have been already described. ${ }^{8,9}$

\section{Cell Cultures, Co-Cultures, And Transfections \\ HEK293T (ATCC, CRL-11268), SiHa (ATCC HTB-35), HeLa (ATCC, CCL-2), and TC-1 (a generous gift of prof.}


Wu, Johns Hopkins Medical Institutes, Baltimore, MD) cells were grown in $10 \%$ heat-inactivated fetal calf serum (FCS)supplemented Dulbecco's modified Eagle's (DMEM, Sigma). Transwell co-cultures were carried out in 6-well plates using Cell Culture Insert Falcon Membrane (25 mm diameter, 0.4 $\mu \mathrm{m}$ pore size, Becton Dickinson). Transfection assays were carried out by the Lipofectamine 2000-based method (Invitrogen, Thermo Fisher Scientific), which, with the exception of HEK293T cells, was performed by adding liposomes to freshly trypsinized cells. In detail, for a $10 \mathrm{~cm}$ diameter dish, $5 \times 10^{6}$ cells were seeded the day before transfection in medium without antibiotics. The day of transfection, the medium volume was brought to $9 \mathrm{~mL}$, and $1 \mathrm{~mL}$ of transfection mix (i.e., $20 \mu \mathrm{L}$ of Lipofectamine plus $30 \mu \mathrm{g}$ of DNA in DMEM) was added after 20 mins incubation at room temperature. After additional $24 \mathrm{hrs}$, the medium was replaced.

\section{Exosome Isolation And Titration}

Twenty-four hours after HEK293T cell transfection, cultures switched to fresh complete medium containing 5\% exosomedeprived FCS, which was obtained after ultracentrifugation at $70,000 \times \mathrm{g}, 3 \mathrm{hrs}$ at $4^{\circ} \mathrm{C}$. Cell supernatants were harvested from 48 to $72 \mathrm{hrs}$ after transfection and centrifuged at $500 \times \mathrm{g}$ for 10 mins. Clarified supernatants were therefore processed for exosome purification by differential centrifugations as previously described. ${ }^{17}$ Briefly, supernatants underwent a first ultracentrifugation at $10,000 \times \mathrm{g}$ for $30 \mathrm{mins}$ at $4^{\circ} \mathrm{C}$, followed by $0.22 \mu \mathrm{m}$ pore-size filtration. Supernatants were then ultracentrifuged at $70,000 \times \mathrm{g}$ for $2.5 \mathrm{hrs}$ at $4^{\circ} \mathrm{C}$. Pelleted vesicles were washed with phosphate-buffered saline (PBS), and ultracentrifuged again at $70,000 \times \mathrm{g}$ for $1 \mathrm{hr}$ at $4^{\circ} \mathrm{C}$. Pellets were finally resuspended in either DMEM (1:200 of the initial supernatant volume) or $0.1 \%$ Triton-X100 TNE (1:300 of the initial volume).

Exosome preparations were quantified by measuring the activity of acetylcholinesterase (AchE), i.e., a typical exosome marker, ${ }^{18}$ through the Amplex Red kit (Molecular Probes) following the manufacturer's recommendations. The AchE activity was measured as $\mathrm{mU} / \mathrm{mL}$, where $1 \mathrm{mU}$ is defined as the amount of enzyme which hydrolyzes 1 pmole of acetylcholine to choline and acetate per minute at $\mathrm{pH} 8.0$ at $37^{\circ} \mathrm{C}$.

\section{Western Blot}

Western blot analysis on lysates of up to $5 \times 10^{6}$ cells was performed by washing cells twice with $1 \times \mathrm{PBS}(\mathrm{pH} 7.4)$ and lysing them for 20 mins on ice with lysis buffer $(20 \mathrm{mM}$ HEPES pH 7.9, $50 \mathrm{mM} \mathrm{NaCl}, 10 \mathrm{mM}$ EDTA, $2 \mathrm{mM}$
EGTA, 0.5\% nonionic detergent IGEPAL CA-630, $0.5 \mathrm{mM}$ dithiothreitol, $20 \mathrm{mM}$ sodium molybdate, $10 \mathrm{mM}$ sodium orthovanadate, $100 \mathrm{mM}$ sodium fluoride, $10 \mu \mathrm{g} / \mathrm{mL}$ leupeptin, $0.5 \mathrm{mM}$ phenylmethylsulfonyl fluoride). Whole cell lysates were centrifuged at $6000 \times \mathrm{g}$ for $10 \mathrm{mins}$ at $4^{\circ} \mathrm{C}$. The protein concentration of cell extracts was determined by the Lowry protein quantitation assay. Aliquots of cell extracts containing 30 to $50 \mu \mathrm{g}$ of total proteins were resolved by $10 \%$ sodium dodecyl sulfate-polyacrylamide gel electrophoresis (SDS-PAGE) and transferred by electroblotting on a $0.45-\mu \mathrm{m}$ pore size nitrocellulose membrane (Amersham) overnight using a Bio-Rad Trans-Blot. Exosomes were lysed and analyzed as described for cell lysates. For immunoassays, membranes were blocked with $5 \%$ non-fat dry milk in PBS containing $0.1 \%$ Triton X-100 for $1 \mathrm{hr}$ at room temperature, then incubated overnight at $4^{\circ}$ $\mathrm{C}$ with specific antibodies diluted in PBS containing $0.1 \%$ Triton X-100. The antibodies used in immunoblots were: 1:2000 diluted sheep polyclonal anti-Nef ARP444 (a generous gift from M. Harris, Leeds, UK); 1:500 diluted rabbit horseradish peroxidase (HRP)-conjugated-anti- $\beta$-Actin (13E5, cat. 5125) (Cell Signaling Technology); 1:500 diluted H-270 rabbit polyclonal anti-Alix (Santa Cruz, cat. sc99010). When appropriate, immune complexes were detected by 1:2000 diluted HRP-conjugated secondary antibodies (Merck, cat. AP132P and AP147P). Finally, signals were revealed by enhanced chemiluminescence reaction (ECL, Millipore).

\section{Co-Immunoprecipitation Assay}

Cells expressing $6 \times$ His-tagged HPV16-E7 and/or Nef ${ }^{\text {mut} /}$ 43M2 were lysed in 1×RIPA lysis buffer (cat. 20188, Millipore) in the presence of protease inhibitors. The cell lysis was carried out also in the presence of $10 \mu \mathrm{M}$ of the HPV16-E7 $10-21$ peptide previously identified as the major binding domain of $43 \mathrm{M} 2^{19}$ to avoid the HPV16-E7$\mathrm{Nef}^{\mathrm{mut} / 43 \mathrm{M} 2}$ binding in cell lysates. A total of $500 \mu \mathrm{g}$ of the cell lysates was incubated o.n. at $4^{\circ} \mathrm{C}$ with $1 \mu \mathrm{g}$ of anti$6 \times \mathrm{His} \mathrm{mAb}$ (cat. 13964A, Bio-Rad), and then for $4 \mathrm{hrs}$ at $4^{\circ} \mathrm{C}$ with $20 \mu \mathrm{L}$ of Dynabeads conjugated with goat antimouse IgGs (Fisher Scientific), previously saturated in FCS. Co-immunoprecipitates were then magnetically separated, washed 5 times in $\mathrm{NaCl} 100 \mathrm{mM}$, Tris-Hcl $30 \mathrm{mM}$, Tween $0.5 \%, \mathrm{pH} 7.4$, and finally revealed by Western blot analysis using both ARP444 sheep anti-Nef and rabbit anti- $6 \times$ His Abs (Bethyl, cat. A190-114A). 


\section{Confocal Microscope Analysis}

A total of $4 \times 10^{4}$ HEK293T cells were seeded on chamber glass slides (BD Biosciences), and co-transfected with vectors expressing HPV16-E7/RFP and either $\mathrm{Nef}^{\mathrm{mut} / \mathrm{GO} \text { or }}$ $\mathrm{Nef}^{\text {mut }} / 43 \mathrm{M} 2$. Twenty-four hours later, cells were labeled with 1:2,000 diluted anti-Nef mAb MATG020 (kindly provided by O. Schwartz, Paris, France), followed by incubation with 1:2500 diluted Alexa 488-conjugated goat anti-mouse (Invitrogen, cat. A28175). Images were acquired using a Leica TCS SP5 confocal microscope and analyzed by the LAS AF version 1.6.3 software (Leica microsystems).

\section{Cytofluorimetric Analysis}

Cells transfected with a GFP-expressing DNA vector were trypsinized, fixed with a $1 \times$ PBS $2 \% \mathrm{v} / \mathrm{v}$ paraformaldehyde (PFA), and the fluorescence analyzed in a BD FACScalibur flow cytometer after labeling with $1 \mu \mathrm{g} / \mathrm{mL}$ of 7 -aminoactinomycin D (AAD) (Sigma) to exclude died cells. For Ki-67 detection, cells were fixed and permeabilized with Cytofix/ Cytoperm solutions (BD Pharmingen) according to the manufacturer's instructions, and then labeled with 1:1000 diluted Alexa 488-conjugated anti-Ki-67 mAb (BioLegend, cat. 350508) for $30 \mathrm{mins}$ at room temperature. Finally, cells were analyzed in a BD FACScalibur cytometer.

Fluorescent exosomes isolated from supernatants of transfected cell cultures were analyzed upon binding with aldehyde/sulfate latex beads (Molecular Probes, Thermo Fisher). To this end, $2 \mathrm{mU}$ equivalent of exosomes were incubated with $5 \mu \mathrm{L}$ of beads overnight at room temperature on a rotating plate, washed, and incubated for $1 \mathrm{hr}$ at $4^{\circ} \mathrm{C}$ with either 1:1000 diluted phycoerythrin (PE)-conjugated anti-CD63 (clone H5C6, BD Pharmingen, cat. 556020 ) or the same concentration of a control isotype. Finally, beads were resuspended and fixed in $1 \times$ PBS-2\% v/v paraformaldehyde, and FACS analyzed.

For the detection of exosome internalization into $\mathrm{SiHa}$ cells, $5 \times 10^{4}$ cells were seeded in microwells and challenged with different amounts of fluorescent exosomes by spinoculation at $1200 \mathrm{~g}$ for $30 \mathrm{mins}$ at $4^{\circ} \mathrm{C}$. Then, the cells were incubated either at $37^{\circ} \mathrm{C}$ or at $4^{\circ} \mathrm{C}$. At different times, i.e., from 1 to $5 \mathrm{hrs}$, the cells were treated for 10 mins with cold trypsin, harvested, washed, fixed, and analyzed by FACS.

\section{Anti-HPV-E7 ELISA}

Methods to produce, purify, and characterize recombinant HPV16-E7, HPV18-E7, and the 43M2 scFv have been already described. ${ }^{14}$ ELISA was carried out as published with minor modifications. Briefly, recombinant HPV16-E7 and HPV18-E7 proteins were adsorbed onto Maxisorp microtiter plates (NUNC, Thermofisher Scientific) overnight at $4{ }^{\circ} \mathrm{C}$. Afterwards, wells were saturated with $2 \%$ non-fat dry milk (Bio-Rad) at $37^{\circ} \mathrm{C}$ for $2 \mathrm{hrs}$, and then incubated at $37^{\circ} \mathrm{C}$ overnight with $3 \mu \mathrm{g} / \mathrm{mL}$ of purified scFv43M2 followed by 1:3000 dilution of anti-flag M2 $\mathrm{mAb}$ (Sigma) for $1 \mathrm{hr}$. Wells were then washed, and a 1:20,000 dilution of anti-mouse HRP-conjugated polyclonal IgG (SBA Inc.) was added for 40 mins. After washing, the antigen-antibody complexes were detected by tetramethylbenzidine (BM blue, POD substrate, Roche). After 30 mins, the enzymatic reaction was stopped, and optical density (OD) measured at $450 \mathrm{~nm}$.

\section{Cell Viability}

Cell viability was assessed by both trypan blue exclusion method and MTS CellTiter $96 \AA{ }^{\circledR} Q_{\text {ueous }}$ One Solution Cell Proliferation Assay (Promega) according to manufacturer's instructions. It is based on the use of the tetrazolium inner salt which in metabolically active cells is reduced by $\mathrm{NAD}(\mathrm{P}) \mathrm{H}$-dependent dehydrogenase enzymes to a colored formazan product that is soluble in cell culture media.

Alternatively, cell viability was monitored after seeding cells in E-plate of xCELLigence RTCA DP system (ACEA Biosciences Inc., San Diego, CA, USA). In detail, $24 \mathrm{hrs}$ after transfection, $4 \times 10^{4}$ cells were seeded in each well, and cell proliferation monitored in real time for 80 to 96 hrs. The impedance (referred to as Cell Index) of each well of RTCA device was monitored at $15-\mathrm{min}$ to $3-\mathrm{hr}$ intervals in the first $24 \mathrm{hrs}$, and at 15-min intervals in the remaining time frames.

In the case of exosome-challenged cells, $4 \times 10^{4}$ cells were resuspended in culture medium in the presence of exosome-deprived FCS and then seeded in duplicate in microwells of xCELLigence RTCA DP system. After 24 hrs, cells were challenged with $2 \mathrm{mU}$ of each exosome preparation in a total of $10 \mu \mathrm{L}$ of medium. Cell Index of each well of RTCA device was monitored at 15-min intervals for the 96-hr observation.

\section{Statistical Analysis}

Statistical tests were performed using Graph Pad Instat3 software. Either nonparametric Mann-Whitney $U$-Test or parametric Student $T$ Test was used to determine $p$ values, as appropriate. All statistical analyses were carried out at a two-sided 5\% significance level. 


\section{Results}

\section{Recovery Of scFv-Engineered Exosomes}

$43 \mathrm{M} 2$ is a previously characterized anti-HPV16-E7 scFv. ${ }^{13,14}$ In the form of intrabody, it efficiently counteracts the proliferation of HPV16-E7 expressing cells by means of the inhibition of HPV16-E7-pRb interaction. ${ }^{19,20}$

We generated DNA vectors expressing the product of fusion of $\mathrm{Nef}^{\text {mut }}$ with this scFv as well as an $\mathrm{scFv}$ binding the glucose oxidase (GO) from Aspergillus niger ${ }^{15}$ as negative control (Figure 1A). Western blot analysis of HEK293T cells transfected with these vectors indicated that both fusion products are produced in the absence of apparent truncated forms. Most important, exosomes isolated from supernatants of transfected cultures were found to upload well-detectable amounts of the $\mathrm{Nef}{ }^{\mathrm{mut}} / \mathrm{scFv}$ fusion product (Figure $1 \mathrm{~B}$ and $\mathrm{C}$ ). Conversely, 43M2 does not associate with exosomes when expressed in the absence of the $\mathrm{Nef}^{\text {mut }}$ fusion (Figure 1D).

We concluded that, as already reported for a large number of both cellular and viral products, ${ }^{8,10-12}$ scFvs also can be efficiently incorporated into exosomes when fused with $\mathrm{Nef}^{\text {mut }}$.

\section{Intracellular Interaction Between HPVI6- E7 And Nef ${ }^{\text {mut }} / 43 \mathrm{M} 2$}

Next, we investigated whether the $43 \mathrm{M} 2 \mathrm{scFv}$ retained the already described HPV16-E7 binding activity when expressed in the form of product of fusion with $\mathrm{Nef}^{\text {mut }}$. It is known that HPV-E7 prevalently accumulates in cell nucleus, where it binds and inactivates the tumor-suppressor protein $\mathrm{pRb}^{21}$ For its part, $\mathrm{Nef}^{\mathrm{mut}}$ prevalently localizes both in cytoplasm and, in view of its $\mathrm{N}$-terminal myristoylated and palmitoylated ends, at the intracellular membranes. ${ }^{4}$

With these premises, we tried to establish whether coexpression of Nef ${ }^{\text {mut }} / 43 \mathrm{M} 2$ and HPV16-E7 would result in changes in HPV16-E7 intracellular localization. HEK293T cells were co-transfected with DNA vectors expressing HPV16-E7/RFP together with either Nef ${ }^{\text {mut }} / 43 \mathrm{M} 2$ or Nef ${ }^{\text {mut/ }}$ GO. After $48 \mathrm{hrs}$, the cells were labeled with an anti-Nef mAb and analyzed by confocal microscope. We observed that the co-expression of $\mathrm{Nef}^{\mathrm{mut}} / 43 \mathrm{M} 2$, but not $\mathrm{Nef}^{\mathrm{mut}} / \mathrm{GO}$, led to a quite impressive HPV16-E7 delocalization from nucleus to cytoplasm (Figure 2A). Consistently, regions of scFv co-localization with HPV16-E7 can be detected in cells expressing

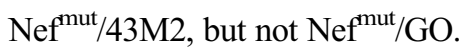

Next, to strengthen the idea that $\mathrm{Nef}{ }^{\mathrm{mut}} / 43 \mathrm{M} 2$ indeed binds HPV16-E7 intracellularly, co-immunoprecipitation assays were carried out. To this end, 293T cells were co-transfected with DNA vectors expressing $\mathrm{Nef}^{\mathrm{mut} / 43 \mathrm{M} 2}$ and an optimized HPV16-E7 sequence ${ }^{16}$ tagged at its C-terminus with $6 \times$ His. As control, cells were either transfected with the DNA vector expressing $\mathrm{Nef}^{\text {mut }} / 43 \mathrm{M} 2$ alone or mock-transfected. After two days, the cells were harvested, lysed, and co-immunoprecipitation assay was performed using an anti- $6 \times$ His $m A b$. Immunocomplexes were revealed with anti-Nef Abs and, as control, rabbit polyclonal anti $6 \times$ His Abs. As shown in Figure $2 \mathrm{~B}, \mathrm{Nef}{ }^{\mathrm{mut}} / 43 \mathrm{M} 2$ was detectable only in immunocomplexes precipitated from lysates of cells co-expressing HPV16-E7. This result confirmed that $\mathrm{Nef}^{\mathrm{mut} / 43 \mathrm{M} 2}$ binds HPV16-E7 inside the cells.

Together, these data strongly support the idea that

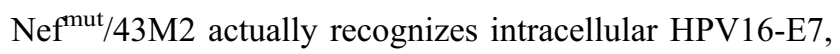
thus indicating that the fusion with $\mathrm{Nef}^{\text {mut }}$ does not affect the scFv binding activity.

\section{The Expression Of $\mathrm{Nef}^{\mathrm{mut}} / 43 \mathrm{M} 2$ Generates A Block Of Proliferation In HPV-Infected Cells}

Next, we investigated whether the Nef ${ }^{\mathrm{mut}} / 43 \mathrm{M} 2$ intracellular binding to HPV16-E7 resulted in a decrease of cell proliferation. To this end, SiHa cells, i.e., a human cell line expressing the whole HPV16 genome, ${ }^{22}$ were transfected with the DNA vectors expressing either $\mathrm{Nef}^{\mathrm{mut}} / 43 \mathrm{M} 2$ or

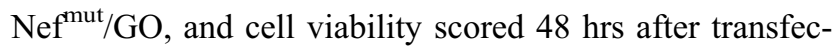
tion by the trypan blue exclusion assay. As controls, $\mathrm{SiHa}$ cells were also transfected with vectors expressing either GFP, $\mathrm{Nef}^{\mathrm{mut}}$, or $43 \mathrm{M} 2$ alone. Of note, accordingly with previously published data, ${ }^{19}$ the intracellular expression of $43 \mathrm{M} 2$ alone was expected to be ineffective in the absence of tag sequences disposing the scFv either into nucleus or at secretory compartments.

Western blot analysis served to verify that both Nef ${ }^{\text {mut }}$ fused scFvs were expressed in $\mathrm{SiHa}$ transfected cells (Figure 3A). In the presence of a transfection efficiency ranging from $25 \%$ to $35 \%$, as assessed by FACS analysis of cells transfected with a GFP-expressing vector (Figure 3B), we noticed a statistically significant decrease in cell proliferation of $\mathrm{Nef}^{\mathrm{mut}} / 43 \mathrm{M} 2$-expressing cells compared to control GFP-transfected cells, i.e, a mean of $1.5 \times 10^{5}$ versus $4 \times 10^{5}$ of total cells, respectively (Figure 3C). The inhibition of cell proliferation associated with a reduction of the expression of the cell proliferation marker Ki-67 (Figure 3C inset). As expected, the expression of neither $\mathrm{Nef}^{\text {mut }}$ nor $43 \mathrm{M} 2$ alone inhibited the cell proliferation, and the same was for cells expressing 

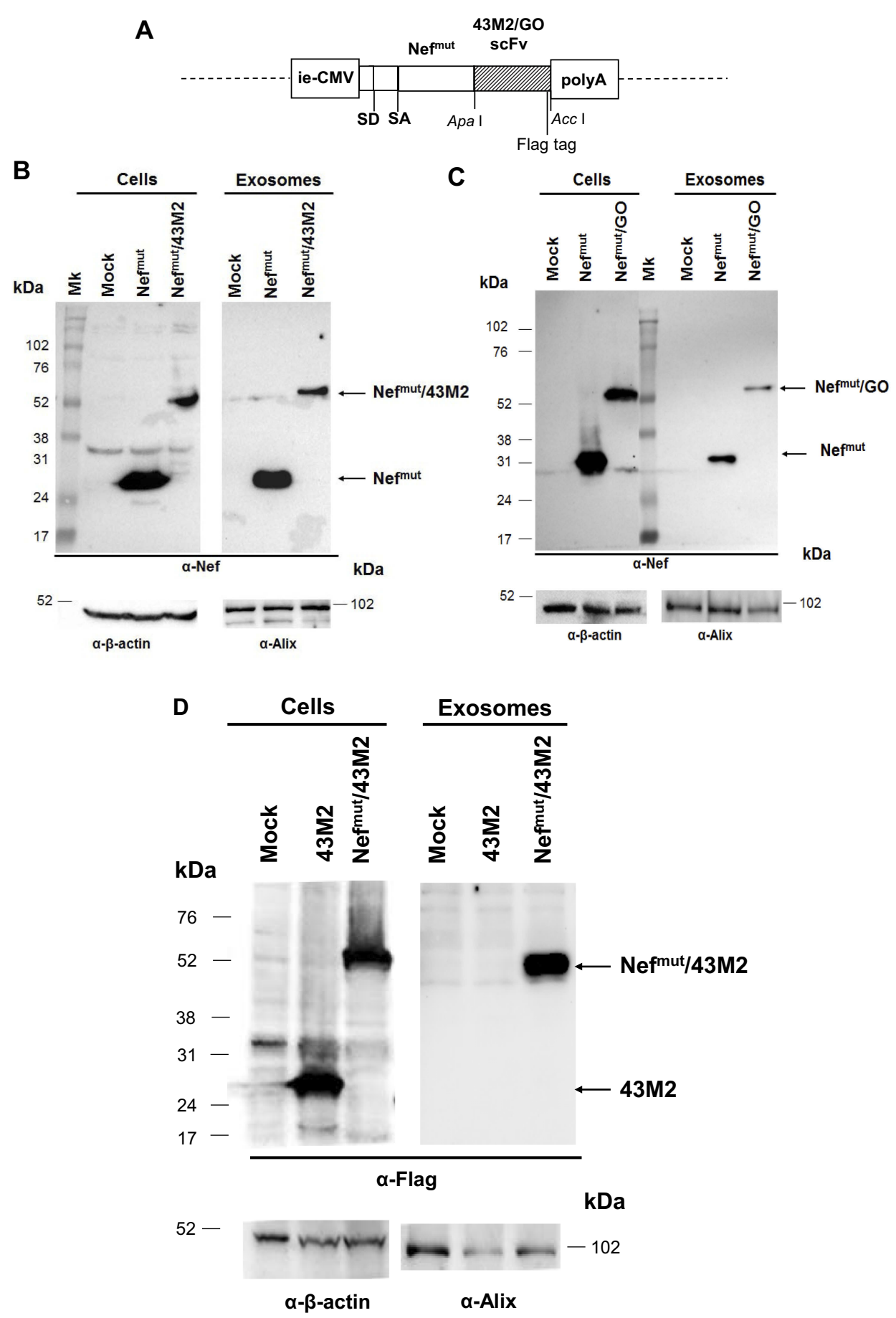

Figure I Design and expression of vectors coding for Nef ${ }^{\text {mut }}$-fused scFvs. (A). Linear map of the DNA vectors expressing either Nef ${ }^{\text {mut } / 43 M 2}$ or Nef ${ }^{\text {mut }} / G O$. Shown are the relevant restriction sites of the pTarget-Nef ${ }^{\text {mut }}$. based expression vector, as well as the flag tag position. le-CMV, immediate-early CMV promoter; SD, major splice donor site; SA, major splice acceptor site; polyA, polyadenylation site. (B, C). Detection of Nef ${ }^{\text {mut }}$-based fusion products in both transfected cells and exosomes. Western blot analysis of both $30 \mu \mathrm{g}$ of cell lysates from HEK293T cells transfected with DNA vectors expressing either 43M2 (B) or GO (C) scFvs fused with $\mathrm{Nef}^{\mathrm{mut}}$, and $2 \mathrm{mU}$ of exosomes purified from the respective supernatants. As control, samples from mock-transfected cells as well as cells transfected with the vector expressing $\mathrm{Nef}^{\text {mut }}$ alone were included. Polyclonal anti-Nef Abs served to detect $\mathrm{Nef}^{\mathrm{mut}}$-based products, while $\boldsymbol{\beta}$-actin and Alix were revealed as cell and exosome markers, respectively. The relevant protein products are highlighted. Molecular weight markers are given in kilodaltons ( $\mathrm{kDa}$ ). The results are representative of three independent experiments. (D) Lack of 43M2 scFv incorporation in exosomes. Western blot analysis of $30 \mu \mathrm{g}$ of cell lysates from HEK293T cells transfected with DNA vectors expressing $43 \mathrm{M} 2 \mathrm{scFv}$ either alone or fused with Nef ${ }^{\text {mut }}$, and of $2 \mathrm{mU}$ of exosomes purified from the respective supernatants. As control, samples from mock-transfected cells were included. Anti-flag tag M2 mAb served to detect 43M2-based products, while $\beta$-actin and Alix were revealed as cell and exosome markers, respectively. Molecular weight markers are given in kilodaltons ( $\mathrm{kDa}$ ). The results are representative of two independent experiments. 

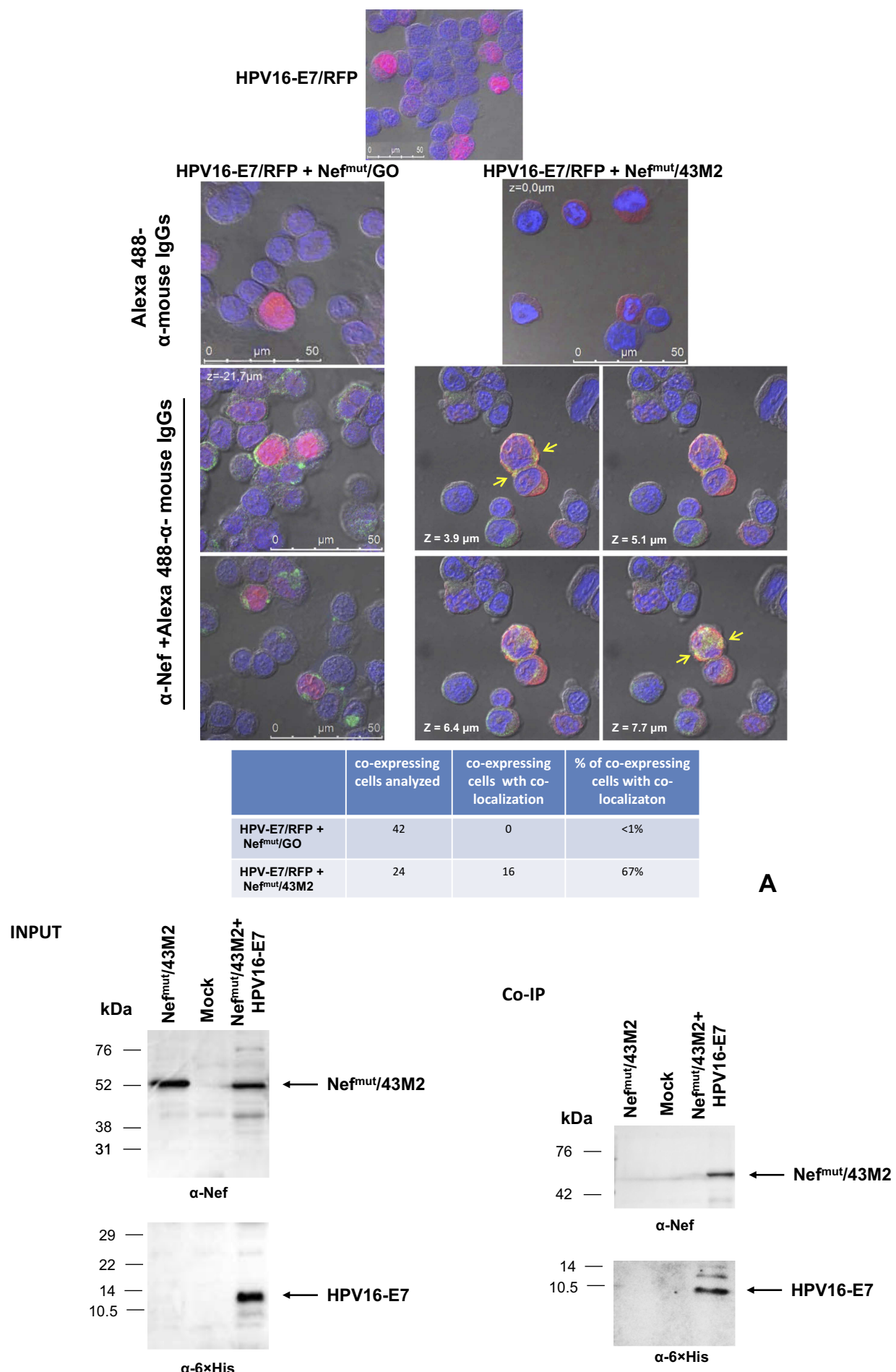

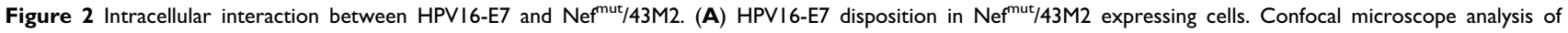
HEK293T cells co-transfected with HPVI6-E7/RFP and either Nef ${ }^{\text {mut }} / 43$ M2 or Nef ${ }^{\text {mut }} /$ GO expressing vectors. Top panels show representative fields from cells either transfected with E7-RFP alone or co-transfected as indicated and labeled with Alexa 488-conjugated anti-mouse IgGs. Below, shown are representative fields from cotransfected cell cultures labeled first with an anti-Nef mAb, and then with Alexa 488-conjugated anti-mouse IgGs. In the case of cells co-transfected with HPVI6-E7/RFP and Nef ${ }^{\text {mut} / 43 M 2 ~ e x p r e s s i n g ~ v e c t o r s, ~ f o u r ~ Z-s t a c k ~ s e c t i o n s ~ a r e ~ s h o w n . ~ H e r e, ~ m a j o r ~ g r e e n ~ t o ~ r e d ~ o v e r l a p p i n g ~ a r e a s ~ a r e ~ i n d i c a t e d ~ b y ~ a r r o w s . ~ D A P I ~(b l u e ~ f l u o r e s c e n c e) ~ w a s ~ u s e d ~}$ to highlight cell nuclei. The images were produced by differential interference contrast. Scale bars are reported. The results are representative of two independent experiments. At the bottom, both numbers and percentages of cells showing fluorescence co-localization are reported. (B) Co-immunoprecipitation assay. 293T cells were co-transfected either with vectors expressing Nef ${ }^{\text {mut }} / 43 \mathrm{M} 2$ and $6 \times$ His-tagged HPVI6-E7, or with Nef ${ }^{\text {mut }} / 43 \mathrm{M} 2$ alone. As control, mock-transfected cells were also included. Forty-eight hours later, cell extracts were incubated with an anti-6×His mAb, and then incubated with anti-mouse IgG-coupled Dynabeads. Immunocomplexes were finally revealed by anti-Nef and, as control, anti- $6 \times$ His Abs. On the top, both anti-Nef and anti- $6 \times$ His tag Western blot analysis on $30 \mu g$ of each cell lysate are shown. At the bottom, shown are both anti-Nef and anti-6×His tag Western blot analysis on immunocomplexes isolated from $500 \mu \mathrm{g}$ of each cell lysate. Molecular weight markers are given in kilodaltons $(\mathrm{kDa})$. The results are representative of three independent experiments. 


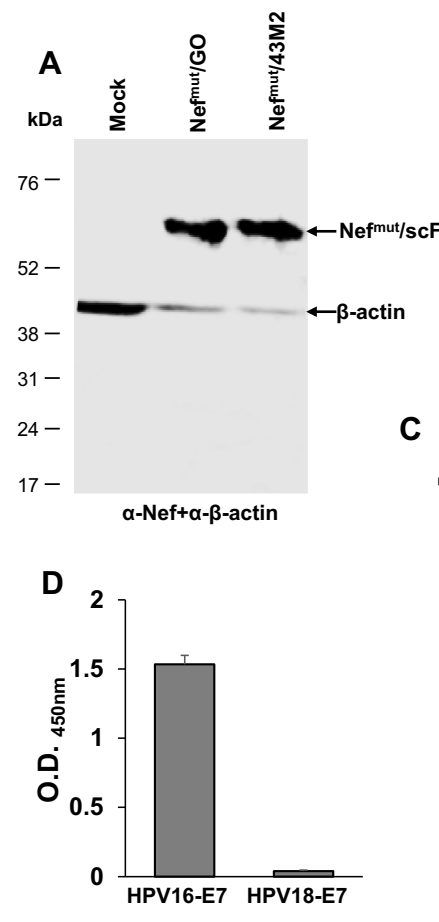

B

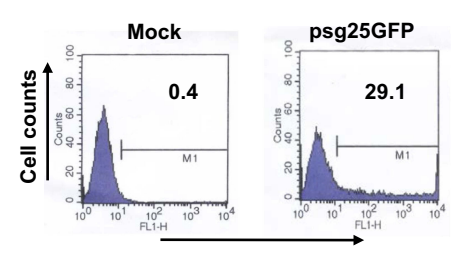

GFP

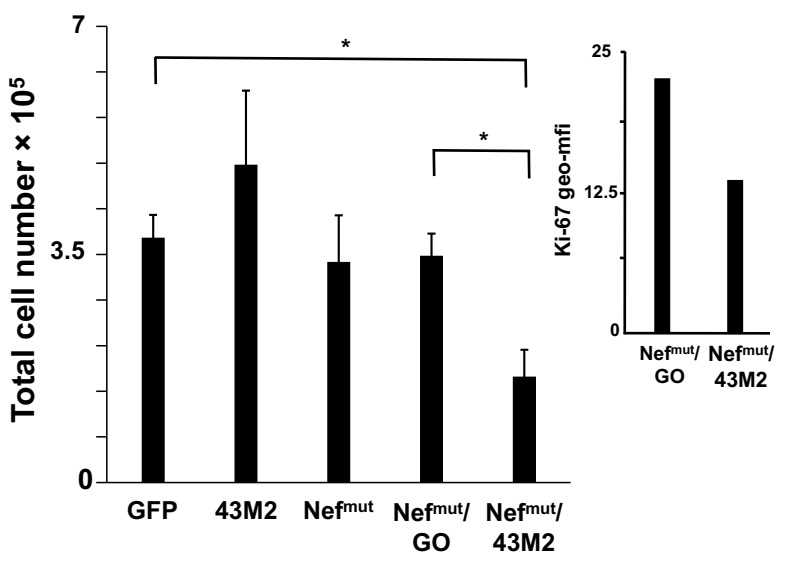

E

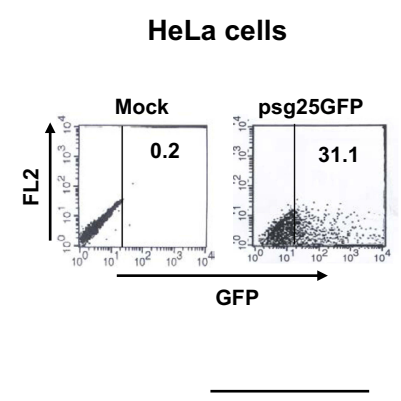

F

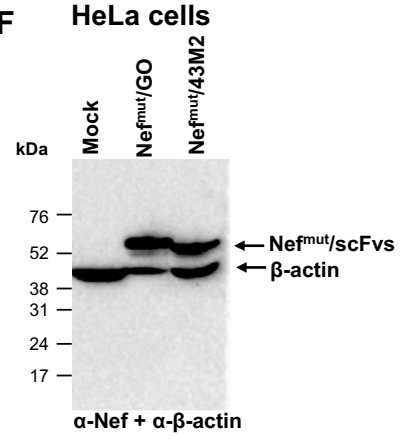

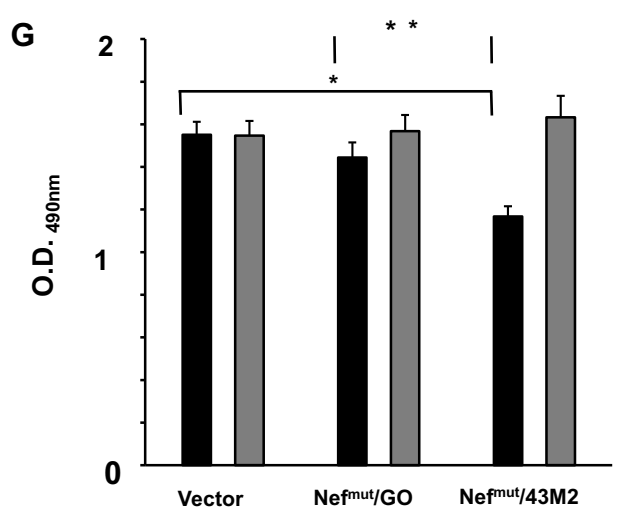

SiHa $\square$ HeLa

Figure 3 Analysis of the anti-proliferative effect of the expression of Nef ${ }^{\text {mut }} / 43 \mathrm{M} 2$ vector in HPVI6-infected cells. (A) Western blot analysis of the expression of Nef ${ }^{\text {mut }}$ derived products in transfected SiHa cells. Filter was revealed by both anti-Nef and HRP-conjugated anti- $\beta$-actin Abs. Molecular mass markers in kDa are reported on the left. Results are representative of three independent experiments. (B) FACS analysis of SiHa cells after transfection with a GFP-expressing vector. As control, mocktransfected cells also were analyzed. The analysis was carried out on 7-AAD negative cells. Percentages of positive cells are indicated. Shown are results representative of six independent experiments. (C) Cell viability of SiHa cells $48 \mathrm{hrs}$ after transfection with the indicated vectors. A total of $2 \times 10^{5}$ cells was transfected with I $\mu \mathrm{g}$ of each DNA vector, and cell viability was scored $48 \mathrm{hrs}$ later by the trypan blue exclusion method. Whatever the DNA vector used, an average of $10-20 \%$ of the dead cells were detected $24 \mathrm{hrs}$ after transfection. Shown are mean values + standard errors of data from four independent experiments carried out in duplicates. ${ }^{*} p<0.05$ by two-tailed MannWhitney $U$-Test. Inset, geometric mean-fluorescence intensity as calculated by FACS analysis conducted on SiHa cells transfected with the indicated vectors and labeled with anti-Ki67 mAb. Shown are the mean values calculated from an experiment performed with duplicate conditions. (D-G) Effects induced by the expression of the Nef ${ }^{\text {mut }} / 43 \mathrm{M} 2$ vector on the proliferation of cells expressing HPVI8-E7. (D) ELISA for the binding of $43 \mathrm{M} 2$ to recombinant E7 from either HPVI6 or HPVI8 strains. The results are representative of three independent experiments carried out in quadruplicate conditions. (E) FACS analysis of HeLa cells 48 hrs after transfection with a GFP-expressing vector. Percentages of DNA vector-expressing cells are reported. The analysis was carried out on 7-AAD negative cells. Results are representative of two independent experiments. (F) Western blot analysis of the expression of Nef ${ }^{\text {mut }}$-derived products in transfected HeLa cells. Filter was revealed by both anti-Nef and HRP-conjugated anti$\boldsymbol{\beta}$-actin Abs. Molecular mass markers in $\mathrm{kDa}$ are reported on the left. Results are representative of three independent experiments. (G) Cell viability of both SiHa and $\mathrm{HeLa}$ cells $48 \mathrm{hrs}$ after transfection as assessed by MTS-based cell proliferation assay. Transfection procedures were as described for panel C, except that, to perform the MTS assay, the cells from each well of the 24 -well plates were split in four microwells of a 96 -well plate 48 hrs after transfection. Shown are the mean values of absorbance at $490_{\mathrm{nm}}(\mathrm{OD})+$ standard errors of the results obtained from four independent experiments performed in quadruplicate. * $p: 0.0002$, ** $p: 0.0054$ by two-tailed Student $T$ Test.

Nef ${ }^{\text {mut } / G O . ~ T h e ~ a n t i-p r o l i f e r a t i v e ~ e f f e c t ~ w a s ~ o b s e r v e d ~ a l s o ~}$ in TC-1 cells, i.e., murine tumor cells constitutively expressing HPV16-E7 ${ }^{23}$ (not shown).

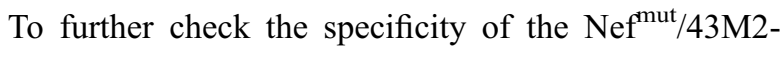
induced effects, we reproduced these experiments using HeLa cells. This cell line expresses the HPV18-E7 
isoform, which is not recognized by the $43 \mathrm{M} 2 \mathrm{scFv}$ as sensed by the ELISA assay whose results are reported in Figure 3D. Cell proliferation was evaluated by the MTSbased assay. In detail, both $\mathrm{SiHa}$ and $\mathrm{HeLa}$ cells were transfected with either $\mathrm{Nef}^{\mathrm{mut}} / 43 \mathrm{M} 2$ or $\mathrm{Nef}^{\mathrm{mut}} / \mathrm{scFvGO}$ expressing vectors. As detected after $48 \mathrm{hrs}$, the transfection efficiency on HeLa cells (Figure 3E) appeared comparable to what we observed with $\mathrm{SiHa}$ cells. Western blot analysis demonstrated that both $\mathrm{Nef}^{\text {mut }}$-fused scFvs were stable in HeLa cells too (Figure 3F). Nonetheless, no reduction of cell proliferation was detectable in $\mathrm{Nef}^{\mathrm{mut}}$ 43M2-expressing HeLa cells compared to cells transfected with the control vectors, in the presence, however, of the expected inhibition in $\mathrm{SiHa}$ cell cultures (Figure 3G).

Taken together, these data indicated that $\mathrm{Nef}^{\text {mut }} / 43 \mathrm{M} 2$ binds intracellular HPV16-E7, thereby inducing a specific anti-proliferative effect.

\section{Proliferation Of HPVI6-Infected Cells Is Impaired By Challenge With Nef ${ }^{\text {mut/ }}$ 43M2-Loaded Exosomes}

We next analyzed the activity of exosome-associated $\mathrm{Nef}^{\mathrm{mut} /}$ 43M2 in challenged HPV-positive cells. In a first instance, we sought to establish whether the cargo of $\mathrm{Nef}^{\text {mut }}$-engineered exosomes could be delivered inside HPV16-expressing cells at detectable extents. To this aim, HEK293T cells were transiently transfected with a Nef ${ }^{\text {mut }} / \mathrm{GFP}$ expressing vector $^{4}$ (Figure 4A), and culture supernatants collected from 48 to $72 \mathrm{hrs}$ thereafter. Fluorescent exosomes were then isolated and analyzed by flow cytometry for the presence of CD63, i.e., a tetraspanin typically expressed on the exosome cell membrane $\mathrm{e}^{24,25}$ (Figure 4B), and by Western blot for the detection of the exosome marker Alix ${ }^{5}$ (Figure 4C). Then, $\mathrm{SiHa}$ cells were challenged with different amounts of the GFP-labeled exosomes and, at different times, FACS analyzed for the intracellular presence of exosome-associated fluorescence. We detected cell-associated fluorescence until $5 \mathrm{hrs}$ after the exosome challenge performed at $37^{\circ} \mathrm{C}$ but not at $4^{\circ} \mathrm{C}$. Furthermore, the percentage of fluorescent cells increased with the doses of challenging exosomes (Figure 4D). This result supported the idea that the cargo of engineered exosomes can be delivered into $\mathrm{SiHa}$ cells preserving an apparently unaltered conformation, considering that the GFP fluorescence relies on its intact secondary and tertiary structures. $^{26}$

Next, we set up experiments to determine the effects of

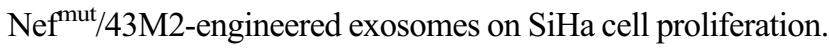

For obvious quantitative reasons, we assumed that the exosome treatment would result in an antiproliferative effect weaker than that observed in DNA-transfected cells. To optimize the readout sensitivity, we monitored cell proliferation through the sensitive, automated, and label-free xCELLigence Real-Time Cell Analysis (RTCA) system. ${ }^{27}$ In the absence of variation in the extra-cellular matrix composition and overall cell morphology, this assay provides a powerful means to monitor cell viability and proliferation in real-time and in a non-invasive way through the measurement of cell culture impedance.

To establish whether the use of the RTCA assay was a suitable tool to evaluate the anti-proliferative effect of $\mathrm{Nef}^{\text {mut }} / 43 \mathrm{M} 2$, both $\mathrm{SiHa}$ and Hela cells were transfected

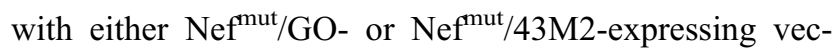
tors. After $24 \mathrm{hrs}$, the cells were seeded in RTCA microwells, and then cell proliferation was followed in real time for $80 \mathrm{hrs}$. Except for a first time lag required for cell adhesion, we noticed both consistent and reproducible lower values of the cell index (CI, directly proportional to cell proliferation) in $\mathrm{SiHa}$ cultures expressing $\mathrm{Nef}^{\mathrm{mut} /}$ 43M2 compared to cells expressing $\mathrm{Nef}^{\mathrm{mut}} / \mathrm{GO}$. Conversely, such a decrease was not detectable in transfected HeLa cells (Figure 5A). We concluded that the RTCA represented a suitable way to evaluate the $\mathrm{Nef}^{\mathrm{mut} /}$ 43M2-induced anti-proliferative effect.

Next, we tried to assess the effects of the treatment with

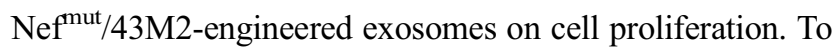
this end, $24 \mathrm{hrs}$ after seeding in the RTCA microwells, both $\mathrm{SiHa}$ and HeLa cells were challenged with equal amounts of exosomes incorporating either $\mathrm{Nef}^{\mathrm{mut}} / 43 \mathrm{M} 2, \mathrm{Nef}^{\mathrm{mut}} / \mathrm{GO}$, or, in the case of SiHa cells only, with void exosomes. Starting from $48 \mathrm{hrs}$ after exosome challenge, the real-time monitoring of the cell cultures revealed a specific reduction in the proliferation of $\mathrm{SiHa}$ cells challenged with $\mathrm{Nef}^{\mathrm{mut} / 43 \mathrm{M} 2-}$ engineered exosomes (Figure 5B).

These results represented a first indication that scFvs delivered in target cells by means of engineered exosomes can preserve their functional activity.

\section{Decreased Proliferation Of HPVI6 Infected Cells Co-Cultured In Transwell Chambers With Cells Producing Nef ${ }^{\text {mut/ }}$ 43M2 Engineered EVs}

To strengthen the significance of the data we obtained through exosome challenge, we designed experiments where the anti-proliferative effect was evaluated in cells 


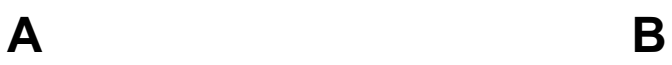

C

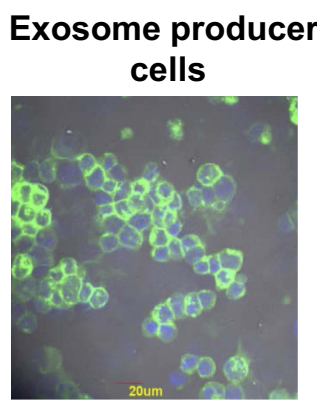

\section{Target cells}

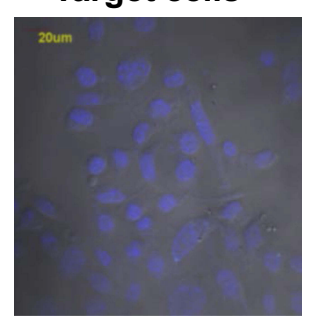

Mock

D
B

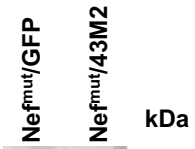

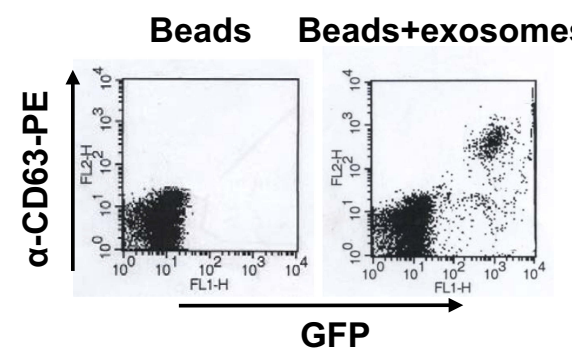

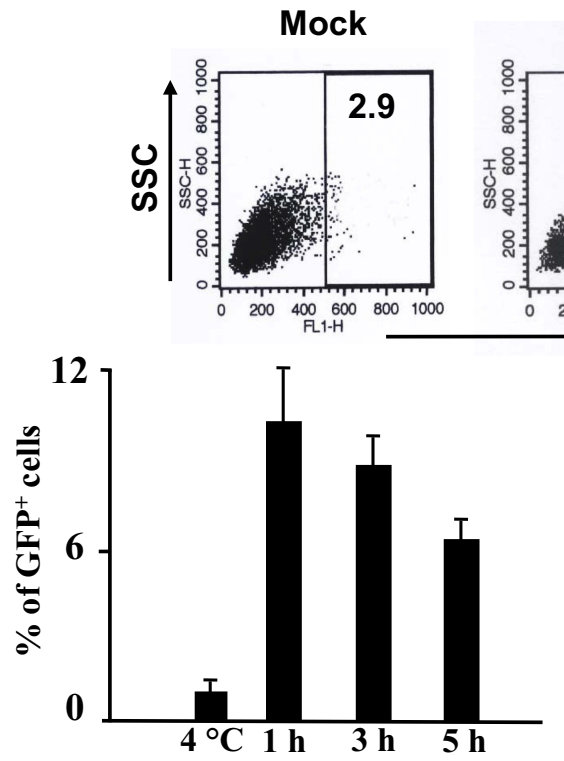

Exo $4{ }^{\circ} \mathrm{C}$

\section{Exo $37^{\circ} \mathrm{C}$}

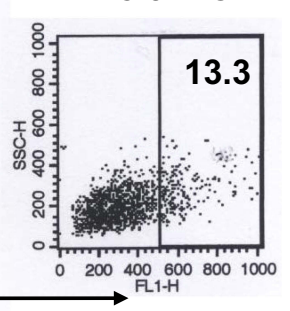

Nefmut/GFP

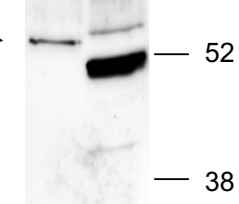

$\alpha-F l a g$

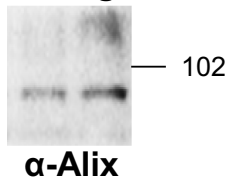

Figure 4 Detection of fluorescent exosomes in challenged $\mathrm{SiHa}$ cells. (A) On the left: fluorescence microscope analysis of HEK293T cells transfected with Nef ${ }^{\text {mut} / G F P ~}$ vector. On the right, the same analysis was carried out on mock-transfected SiHa cells. The cell nuclei were stained with DAPI (blue fluorescence). (B) FACS analysis of fluorescent exosomes produced by Nef ${ }^{\text {mut} / G F P ~ e x p r e s s i n g ~ c e l l s . ~ E x o s o m e s ~ w e r e ~ b o u n d ~ t o ~ s u r f a c t a n t-f r e e ~ w h i t e ~ a l d e h y d e / s u l f a t e ~ l a t e x ~ b e a d s ~ a n d ~ t h e n ~ l a b e l e d ~ w i t h ~ P E-~}$ conjugated anti-CD63 mAbs. The analysis included singularly dispersed beads only, as identified through the FSC/SSC plots. Shown are the results representative of six independent experiments. (C) Western blot analysis of $2 \mathrm{mU}$ of exosomes purified from the supernatants of Nef ${ }^{\mathrm{mut}} / \mathrm{GFP}$ expressing cells. As control, exosomes from cells transfected with the vector expressing Nef ${ }^{\text {mut }} / 43 \mathrm{M} 2$ were included. Polyclonal anti-Nef Abs served to detect Nef ${ }^{\text {mut }}$-based products, while Alix was revealed as exosome marker. Molecular weight markers are given in kilodaltons $(\mathrm{kDa})$. The results are representative of two independent experiments. (D) FACS analysis on SiHa cells challenged with GFP-fluorescent exosomes. A total of $2 \times 10^{4} \mathrm{SiHa}$ cells was challenged with different amounts of fluorescent exosomes (i.e., from 80 to $240 \mu \mathrm{U}$ ). After spinoculation, cells were incubated either at either $4^{\circ} \mathrm{C}$ or $37^{\circ} \mathrm{C}$. At different times, cells were detached with cold trypsin, washed, fixed, and FACS analyzed. On the top, shown are the raw data from cells challenged or not (Mock) with $160 \mu \mathrm{U}$ of exosomes, and analyzed $3 \mathrm{hrs} \mathrm{later.} \mathrm{As} \mathrm{control,} \mathrm{the} \mathrm{results} \mathrm{from} \mathrm{exosome-challenged} \mathrm{cells} \mathrm{incubated} \mathrm{at} 4^{\circ} \mathrm{C}$ are shown. On the bottom left, shown are the results from FACS analysis of cells challenged with $160 \mu \mathrm{U}$ of exosomes and harvested at different times. As control, conditions where exosome-challenged cells were incubated at $4^{\circ} \mathrm{C}$ and harvested at the latest time point were included. On the bottom right, shown are the results from FACS analysis of cells challenged with the indicated amounts of fluorescent exosomes, and harvested $3 \mathrm{hrs}$ after spinoculation. As control, data from the analysis of cells challenged with the highest amounts of exosomes and incubated at $4^{\circ} \mathrm{C}$ were included. The results are presented as mean values $+\mathrm{SD}$ of triplicates after subtraction of background values (i.e., the fluorescence levels of mock-challenged cells), and are representative of two independent experiments.

growing in the continuous presence of $\mathrm{Nef}^{\text {mut }} / 43 \mathrm{M} 2$-engineered EVs. To this end, we set up transwell co-cultures comprising donor cells, i.e., HEK293T cells transiently transfected with $\mathrm{Nef}^{\text {mut }}$-based DNA vectors which were seeded in the upper chamber, and either SiHa or HeLa target cells placed in the lower one. After four days, the proliferation of both $\mathrm{SiHa}$ and HeLa cells was assessed by the MTS-based colorimetric assay. A significant reduction of cell proliferation was detected in SiHa cells co-cultured with the donor Nef ${ }^{\text {mut }}$ /43M2-expressing HEK293T cells, whereas no differences were observed using $\mathrm{HeLa}$ as target cells (Figure 5C).

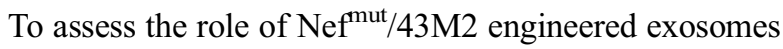
in the inhibition of cell proliferation, we repeated the transwell experiments in the presence or absence of $1 \mu \mathrm{M}$ of both GW4869 and spiroepoxide, i.e., two inhibitors of exosome 
A

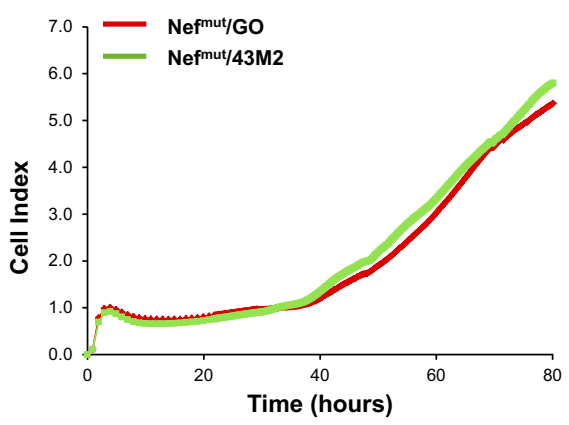

B

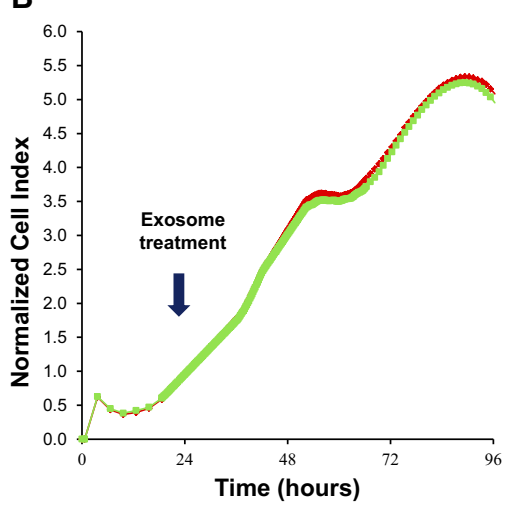

SiHa cells

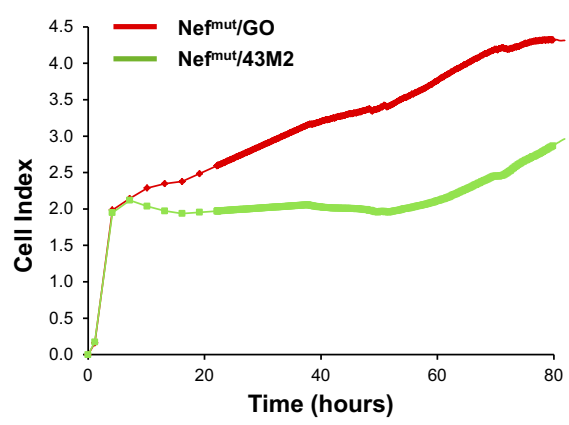

SiHa cells

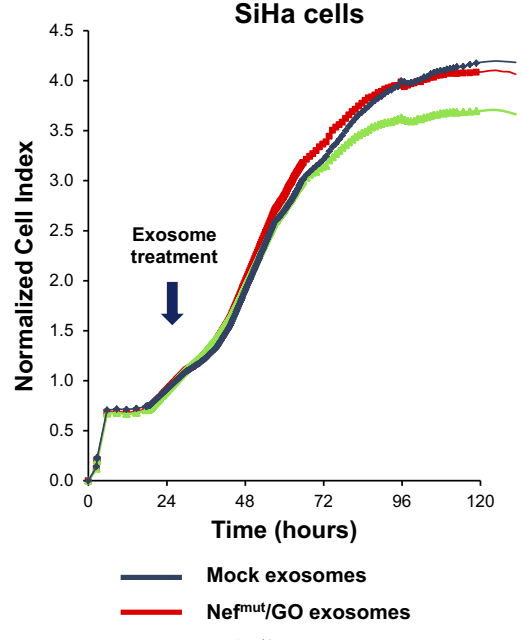

Nef ${ }^{\text {mut/43M2 exosomes }}$
C

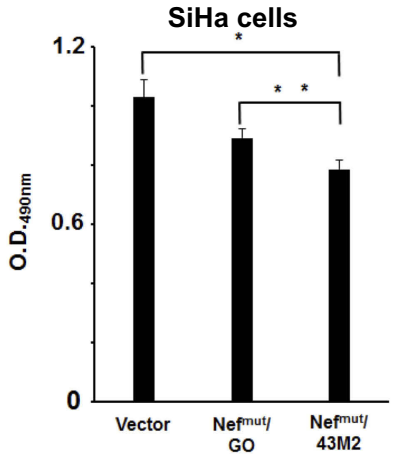

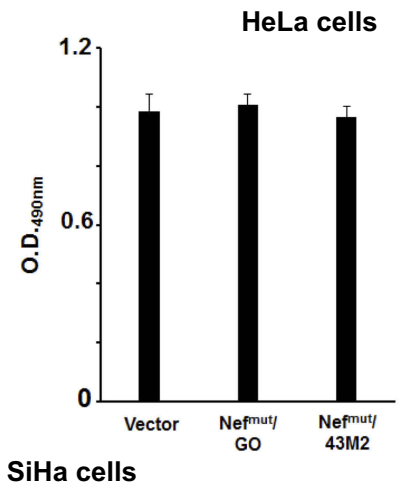

D

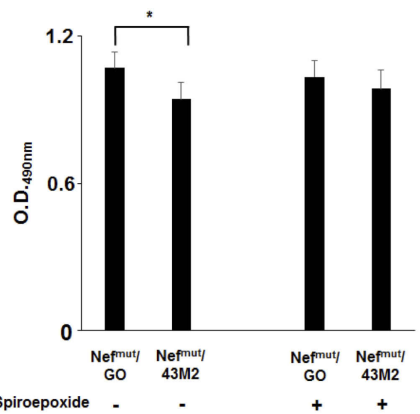

Figure 5 Functional analysis of $\mathrm{Nef}^{\text {mut }} / 43 \mathrm{M} 2$ engineered exosomes. (A) Viability of SiHa cells after challenge with $\mathrm{Nef}$ mut/43M2-uploading exosomes. RTCA proliferation assay in both

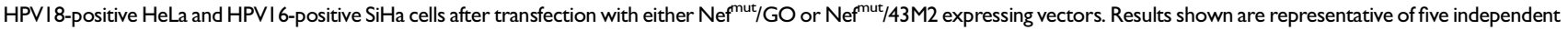
experiments. (B) RTCA proliferation assay in both HeLa and SiHa cells challenged with exosomes uploading either Neffut/GO or Neffut/43M2. As an additional control, SiHa cells were challenged with equivalent amounts of exosomes isolated from the supernatants of mock-transfected cells. Arrows indicate the time of exosome treatment, i.e., 24 hrs after seeding. Results are expressed as normalized cell index, i.e., the ratio between cell index at a given time and cell index at the time of exosome treatment, and are representative of two independent experiments. (C) Viability of SiHa cells co-cultured in transwell chambers with HEK293T cells producing Nef ${ }^{\text {mut }} / 43 \mathrm{M} 2$ engineered EVs. HEK293T cells were transfected with vectors expressing either Nefmut/43M2, Nef "mut/GO, or empty vector. After 24 hrs, transfected cells were seeded in the upper transwell chamber while either SiHa or Hela cells were plated in the lower one. Four days later, cell viability was assessed by MTS-based cell proliferation assay. At this time, cells from each well were detached, resuspended in $0.4 \mathrm{~mL}$ of complete medium, and four microwells of a 96-well plate were seeded with $100 \mu \mathrm{L}$ of each cell culture. Shown are mean OD values + standard errors from the results of six independent experiments performed in quadruplicates. ${ }^{*}$ : $0.0094 ; * *$ p: 0.0274 by two-tailed Mann-Whitney U-Test. (D) Cell viability as assessed by MTS-based cell proliferation assay 4 days after setting the co-culture of SiHa cells with HEK293T cells previously transfected with the indicated vectors, and carried out in the presence or absence of I $\mu M$ GW4869 and spiroepoxide. SiHa cell cultures were processed for the MTS assay as described for panel A. Shown are mean OD values + standard errors from the results of four independent experiments conducted in quadruplicates. * ${ }^{*}: 0.0396$ by two-tailed Student $T$ Test. Differences in cell viability between SiHa cells co-cultivated with donor cells transfected with the two different vectors in the presence of the inhibitors were not statistically significant ( $p$ : $0.547 \mathrm{I}$ by two-tailed Student $T$ Test).

biosynthesis. ${ }^{28-33}$ In our hands, the actual inhibition of exosome release from HEK293T cells treated with $1 \mu \mathrm{M}$
GW4869 and spiroepoxide ranged from $60 \%$ to $80 \%$, as assessed through the acetylcholinesterase assay (not 
shown). Interestingly, treatment with the inhibitors restored the cell proliferation levels of SiHa cells co-cultured with

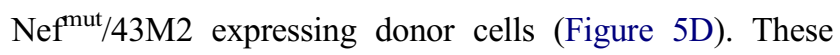
results strongly suggested that the proliferation of target cells was indeed affected by the release of $\mathrm{Nef}^{\mathrm{mut}} / 43 \mathrm{M} 2$ engineered exosomes from donor cells.

Together with what we observed by challenging $\mathrm{SiHa}$ cells with cell-free exosomes, these results support the idea that $\mathrm{Nef}^{\text {mut }}$-based engineered EVs can represent an efficient tool to deliver scFvs inside target cells.

\section{Discussion}

ScFvs, in their different configurations, can represent effective surrogates of tetrameric Abs, since they were shown to reproduce both agonist and antagonist activities. As with classic Abs, however, plasma membrane hinders their access to the intracellular milieu. Developing strategies aimed at favoring $\mathrm{scFv}_{\mathrm{v}}$ intracellular delivery have been a matter of major interest in the last decade. Previously described methods are based on coupling scFvs with a number of polymers/ nanoparticles, e.g., cationic liposomes, ${ }^{34,35}$ or cell-penetrating peptides. ${ }^{36,37}$ Although in both cases intracellular antigens have been successfully targeted, major limitations in possible therapeutic applications still remained. The aim of our investigations was achieving the proof-of-concept for a novel strategy of intracellular scFv delivery potentially suitable for clinical development. The idea was based on our recent finding concerning the possibility to generate engineered EVs through a DNA vector expressing the Nef ${ }^{\text {mut }}$ exosome-anchoring protein fused with polypeptides of interest. ${ }^{11}$ When the system is translated in vivo, engineered EVs protect their cargo from degradation factors present in both extracellular milieu and serum, and can safely deliver it upon entry into target cells. In the case scFvs are uploaded into EVs, intracellular therapeutic targets can be inactivated.

To evaluate the effectiveness of our strategy in an in vitro system, we considered the anti-HPV16-E7 43M2 scFv. ${ }^{13,14,19}$ In the form of intrabody, this $\mathrm{scFv}$ has been previously characterized for its ability to counteract the proliferative effect of HPV16-E7 both in vitro and in vivo. ${ }^{13,20}$ Here, we show that both $43 \mathrm{M} 2$ and GO scFvs are readily uploaded into EVs when fused to the Nef ${ }^{\text {mut }}$ C-terminus. In this form, 43M2 strongly reduces the nuclear accumulation of HPV16-E7 as assessed by confocal microscope analysis. In addition, the well-detectable areas of $\mathrm{Nef}^{\mathrm{mut}} / 43 \mathrm{M} 2-\mathrm{HPV} 16-\mathrm{E} 7$ co-localization were consistent with the idea that the HPV16-E7 translocation was consequence of the interaction with $43 \mathrm{M} 2$. This is a relevant issue since it was previously shown that $43 \mathrm{M} 2$ counteracts the HPV16-E7 activity exclusively when provided with signals for intracellular localization at either nucleus or secretory compartment. ${ }^{19}$ Hence, fusion with Nef ${ }^{\text {mut }}$ overcomes the need to modify $43 \mathrm{M} 2$ to optimize its effect against the target protein. It is conceivable that the strong affinity of $\mathrm{Nef}^{\text {mut }}$ for intracellular membranes favors both the stability of $\mathrm{Nef}^{\mathrm{mut}} / 43 \mathrm{M} 2$ and its interaction with neo-synthesized HPV16-E7.

$\mathrm{Nef}^{\text {mut }}$ /43M2 expressed in transfected cells was shown to specifically inhibit cell proliferation of HPV16-E7 expressing cells. This conclusion was drawn through trypan blue exclusion test, Ki-67 detection, MTS, and RTCA assays. Hence, $43 \mathrm{M} 2$ preserves its anti-proliferative activity even when fused with Nef ${ }^{\text {mut }}$. The overall potency of this effect appeared comparable to what previously described when 43M2 fused to a signal for retention in the endoplasmic reticulum was expressed intracellularly. ${ }^{13}$

As for the mechanism underlying the anti-proliferative effect in transfected cell cultures, it should be considered that at least part of the $\mathrm{Nef}^{\text {mut }} / 43 \mathrm{M} 2$ molecules could associate with exosomes released by DNA-vector expressing cells, thus contributing to HPV16-E7 neutralization in bystander cells. This mechanism may account for the extents of cell proliferation inhibition sometime exceeding the percentages of DNA transfected cells as evaluated by FACS analysis. This hypothesis is consistent with the results we obtained from the experiments performed by challenging SiHa cells with engineered exosomes, as well as those from co-cultures of SiHa cells with HEK293T cells producing $\mathrm{Nef}^{\mathrm{mut}} / 43 \mathrm{M} 2$-uploaded EVs. In the latter instance, the fact that treatment of transwell co-cultures with inhibitors of exosome biosynthesis strongly reduced the anti-proliferative effect highlighted the role of engineered exosomes in the inhibitory effect.

The impairment of cell proliferation consequent of the treatment with cell-free engineered exosomes appeared somewhat reduced and delayed compared to what we detected in Nef ${ }^{\text {mut }} / 43 \mathrm{M} 2$ transfected cells. Likely, quantitative differences in the actual intracellular $\mathrm{Nef}^{\text {mut }} / 43 \mathrm{M} 2$ availability may account for such apparent discrepancy. In fact, it is conceivable that, whereas the expression of transfected DNA leads to a both continuous and massive production of $\mathrm{Nef}^{\mathrm{mut}} / 43 \mathrm{M} 2$, conversely providing cells with a single pulse of engineered exosomes likely results in a less abundant and, most important, temporarily limited availability of the anti- HPV16-E7 scFv. In addition, efficiency of both nanovesicle cell entry and escape from 
intracellular degradative pathways may influence the overall scFv availability in EV-challenged cells.

\section{Conclusion}

Engineering EVs with scFvs has the potential to be exploited as a novel therapeutic approach to target intracellular pathogenic factors. In vivo, this strategy could be applied by engineering endogenous EVs through the intramuscular injection of $\mathrm{Nef}^{\text {mut }}$-related DNA vectors, as we already described. ${ }^{4,10}$ The delivery of DNA expressing Nef $^{\text {mut }}$-fused scFvs, possibly also by viral vectors, would result in a continuous source of engineered EVs. These nanovesicles can safely deliver therapeutic scFvs into bystander cells, where the binding to specific intracellular pathogenic factors can generate the desired effect.

Previous literature data report protein engineering of EVs essentially through manipulation of membrane-associated proteins. For instance, tetraspanins (e.g., CD9, CD63, CD81), ${ }^{38,39}$ spontaneously associating with exosome membranes at high levels, as well as proteins of the endosome/

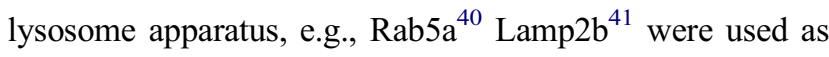
scaffolds to engineer exosomes with fluorescent proteins. Similarly, the transmembrane domain of platelet-derived growth factor receptor ${ }^{42}$ and the $\mathrm{C} 1 \mathrm{C} 2$ domains of lactadherin $^{43,44}$ represented the platform of chimeric proteins expressed in exosome membranes. In addition, specific cell targeting of EVs was achieved by building chimeric proteins recognizing specific cell membrane receptors, for instance through the fusion with receptor-specific scFvs. As an example, exosomes displaying anti-HER2 scFv to target cancer mammary cells were recently described by two independent groups. ${ }^{45,46}$ Similarly, exosomes engineered with anti-CD19 $\mathrm{scFv}$ fused with CD63 were shown to efficiently target lymphoma cells. ${ }^{47}$

With these premises, vectors co-expressing $\mathrm{Nef}^{\text {mut }}$ fused with therapeutic scFvs and membrane molecules engineered with receptor-specific scFvs have the potential to generate EVs efficiently expanding the $\mathrm{scFv}$-induced therapeutic effect to appropriate bystander cells.

\section{Ethics}

The use of all cell lines had Istituto Superiore di Sanità (ISS) review board approval.

\section{Acknowledgment}

We thank Carlo Bonchi for kindly providing the RTCA DP system and Pietro Arciero for technical support.

\section{Disclosure}

The authors report no conflicts of interest in this work.

\section{References}

1. Andersen DC, Reilly DE. Production technologies for monoclonal antibodies and their fragments. Curr Opin Biotechnol. 2004;15 (5):456-462. doi:10.1016/j.copbio.2004.08.002

2. Ahmad ZA, Yeap SK, Ali AM, Ho WY, Alitheen NBM, Hamid M. scFv antibody: principles and clinical application. Clin Dev Immunol. 2012;2012(2):1-15. doi:10.1155/2012/980250

3. Lo ASY, Zhu Q, Marasco WA. Intracellular antibodies (intrabodies) and their therapeutic potential. Handb Exp Pharmacol. 2008;181:343-373.

4. Di Bonito P, Chiozzini C, Arenaccio C, et al. Antitumor HPV E7specific CTL activity elicited by in vivo engineered exosomes produced through DNA inoculation. Int J Nanomedicine. 2017;12:45794591. doi:10.2147/IJN

5. van Niel G, D'Angelo G, Raposo G. Shedding light on the cell biology of extracellular vesicles. Nat Rev Mol Cell Biol. 2018;19 (4):213-228. doi:10.1038/nrm.2017.125

6. Schorey JS, Cheng Y, Singh PP, Smith VL. Exosomes and other extracellular vesicles in host-pathogen interactions. EMBO Rep. 2015;16(1):24-43. doi:10.15252/embr.201439363

7. György B, Szabó TG, Pásztói M, et al. Membrane vesicles, current state-of-the-art: emerging role of extracellular vesicles. Cell Mol Life Sci. 2011;68(16):2667-2688. doi:10.1007/s00018-011-0689-3

8. Lattanzi L, Federico M. A strategy of antigen incorporation into exosomes: comparing cross-presentation levels of antigens delivered by engineered exosomes and by lentiviral virus-like particles. Vaccine. 2012;30(50):7229-7237. doi:10.1016/j.vaccine.2012.10.010

9. D’Aloja P, Santarcangelo AC, Federico M, Arold S, Baur A. Genetic and functional analysis of the human immunodeficiency virus (HIV) type 1-inhibiting F12-HIVnef allele. J Gen Virol. 2001;82(11):27352745. doi:10.1099/0022-1317-82-11-2735

10. Anticoli S, Manfredi F, Chiozzini C, et al. An exosome-based vaccine platform imparts cytotoxic $\mathrm{t}$ lymphocyte immunity against viral antigens. Biotechnol J. 2018;13(4):e1700443. doi:10.1002/biot.v13.4

11. Di Bonito P, Ridolfi B, Columba-Cabezas S, et al. HPV-E7 delivered by engineered exosomes elicits a protective $\mathrm{CD} 8+\mathrm{T}$ cell-mediated immune response. Viruses. 2015;7(3):1079-1099. doi:10.3390/v7031079

12. Anticoli S, Falcone E, Ruggieri A, Federico M. Engineered exosomes boost the HCV NS3-specific CD8+ T lymphocyte immunity in humans. Trials Vaccinol. 2016;5:105-110. doi:10.1016/j.trivac.2016.05.001

13. Accardi L, Donà MG, Di Bonito $\mathrm{P}$, Giorgi C. Intracellular anti-E7 human antibodies in single-chain format inhibit proliferation of HPV16-positive cervical carcinoma cells. Int J Cancer. 2005;116 (4):564-570. doi:10.1002/(ISSN)1097-0215

14. Donà MG, Giorgi C, Accardi L. Characterization of antibodies in single-chain format against the E7 oncoprotein of the Human papillomavirus type 16 and their improvement by mutagenesis. BMC Cancer. 2007;7(1):25. doi:10.1186/1471-2407-7-25

15. Ascione A, Flego M, Zamboni S, De Cinti E, Dupuis ML, Cianfriglia $\mathrm{M}$. Isolation and characterization of the human monoclonal antibodies $\mathrm{C} 10$ in single-chain fragment variable $(\mathrm{scFv})$ format to glucose oxidase from Aspergillus niger. Hybrid Hybridomics. 2004;23 (6):380-384. doi:10.1089/hyb.2004.23.380

16. Arregui AC, Juarez V, Zur Hausen H. A synthetic E7 gene of Human Papilloma Type 16 that yields enhanced expression of the protein in mammalian cells and is useful for DNA immunization studies. $J$ Virol. 2003;77(8):4928-4937. doi:10.1128/JVI.77.8.4928-4937.2003

17. Théry C, Amigorena S, Raposo G, Clayton A. Isolation and characterization of exosomes from cell culture supernatants and biological fluids. Curr Protoc Cell Biol. 2006;30(1):3.22.1-3.22.29. doi:10.1002/0471143030.cb0322s30 
18. Rieu S, Géminard C, Rabesandratana H, Sainte-Marie J, Vidal M. Exosomes released during reticulocyte maturation bind to fibronectin via integrin $\alpha 4 \beta 1$. Eur J Biochem . 2000;267(2):583-590. doi:10.1046/j.14321327.2000.01036.x

19. Accardi L, Donà MG, Mileo AM, et al. Retinoblastoma-independent antiproliferative activity of novel intracellular antibodies against the E7 oncoprotein in HPV 16-positive cells. BMC Cancer. 2011;11 (1):17. doi:10.1186/1471-2407-11-17

20. Accardi L, Paolini F, Mandarino A, et al. In vivo antitumor effect of an intracellular single-chain antibody fragment against the E7 oncoprotein of human papillomavirus 16. Int $J$ Cancer. 2014;134 (11):2742-2747. doi:10.1002/ijc.28604

21. Moody CA, Laimins LA. Human papillomavirus oncoproteins: pathways to transformation. Nat Rev Cancer. 2010;10(8):550-560. doi: $10.1038 / \mathrm{nrc} 2886$

22. Friedl F, Kimura I, Osato T, Ito Y. Studies on a new human cell line (SiHa) derived from carcinoma of uterus. I. Its establishment and morphology. Exp Biol Med. 1970;135(2):543-545. doi:10.3181/ 00379727-135-35091a

23. Lin KY, Guarnieri FG, Staveley-O'Carroll KF, et al. Treatment of established tumors with a novel vaccine that enhances major histocompatibility class II presentation of tumor antigen. Cancer Res. 1996;56(1):21-26.

24. Arenaccio C, Federico M. The multifaceted functions of exosomes in health and disease: an overview. Adv Exp Med Biol. 2017;998:3-19.

25. Conde-Vancells J, Rodriguez-Suarez E, Embade N, et al. Characterization and comprehensive proteome profiling of exosomes secreted by hepatocytes. J Proteome Res. 2008;7(12):5157-5166. doi: $10.1021 / \mathrm{pr} 8004887$

26. Kremers G-J, Gilbert SG, Cranfill PJ, Davidson MW, Piston DW. Fluorescent proteins at a glance. J Cell Sci. 2011;124(15):157-160. doi:10.1242/jcs.072744

27. Huang Y, Burns DJ, Rich BE, et al. Development of a test that measures real-time HER2 signaling function in live breast cancer cell lines and primary cells. BMC Cancer. 2017;17(1):199. doi: $10.1186 / \mathrm{s} 12885-017-3181-0$

28. Chairoungdua A, Smith DL, Pochard P, Hull M, Caplan MJ. Exosome release of $\beta$-catenin: a novel mechanism that antagonizes Wnt signaling. J Cell Biol. 2010;190(6):1079-1091. doi:10.1083/ jcb.201002049

29. Kogure T, Lin W-L, Yan IK, Braconi C, Patel T. Intercellular nanovesicle-mediated microRNA transfer: a mechanism of environmental modulation of hepatocellular cancer cell growth. Hepatology. 2011;54(4):1237-1248. doi:10.1002/hep.24504

30. Kosaka N, Iguchi H, Yoshioka Y, Takeshita F, Matsuki Y, Ochiya T. Secretory mechanisms and intercellular transfer of MicroRNAs in living cells. J Biol Chem. 2010;285(23):17442-17452. doi:10.1074/ jbc.M110.107821

31. Kosaka N, Iguchi H, Yoshioka Y, Hagiwara K, Takeshita F, Ochiya T. Competitive interactions of cancer cells and normal cells via secretory microRNAs. J Biol Chem. 2012;287(2):1397-1405. doi:10.1074/ jbc.M111.288662

32. Trajkovic K, Hsu C, Chiantia S, et al. Ceramide triggers budding of exosome vesicles into multivesicular endosomes. Science. 2008;319 (5867):1244-1247. doi:10.1126/science.1153124
33. Yuyama K, Sun H, Mitsutake S, Igarashi Y. Sphingolipid-modulated exosome secretion promotes clearance of amyloid- $\beta$ by microglia. J Biol Chem. 2012;287(14):10977-10989. doi:10.1074/jbc.M111.324616

34. Lu RM, Chang YL, Chen MS, Wu HC. Single chain anti-c-Met antibody conjugated nanoparticles for in vivo tumor-targeted imaging and drug delivery. Biomaterials. 2011;32(12):3265-3274. doi:10. 1016/j.biomaterials.2010.12.061

35. Saeed M, van Brakel M, Zalba S, et al. Targeting melanoma with immunoliposomes coupled to anti-MAGE A1 TCR-like single-chain antibody. Int J Nanomedicine. 2016;11:955. doi:10.2147/IJN

36. Xun Y, Pan Q, Tang Z, et al. Intracellular-delivery of a single-chain antibody against hepatitis B core protein via cell-penetrating peptide inhibits hepatitis B virus replication in vitro. Int $J$ Mol Med. 2013;31 (2):369-376. doi:10.3892/ijmm.2012.1210

37. Lim KJ, Sung BH, Shin JR, et al. A cancer specific cell-penetrating peptide, BR2, for the efficient delivery of an scfv into cancer cells. PLoS ONE. 2013;8(6):e66084. doi:10.1371/journal.pone.0066084

38. Wiklander OP, Nordin JZ, O'Loughlin A, et al. Extracellular vesicle in vivo biodistribution is determined by cell source, route of administration and targeting. $J$ Extracell Vesicles. 2015;4:26316. doi:10.3402/jev.v4.26316

39. Stickney Z, Losacco J, McDevitt S, Zhang Z, Lu B. Development of exosome surface display technology in living human cells. Biochem Biophys Res Commun. 2016;472(1):53-59. doi:10.1016/j.bbrc.2016.02. 058

40. Suetsugu A, Honma K, Saji S, Moriwaki H, Ochiya T, Hoffman RM. Imaging exosome transfer from breast cancer cells to stroma at metastatic sites in orthotopic nude-mouse models. Adv Drug Deliv Rev. 2013;65(3):383-390. doi:10.1016/j.addr.2012.08.007

41. Alvarez-Erviti L, Seow Y, Yin H, Betts C, Lakhal S, Wood MJA. Delivery of siRNA to the mouse brain by systemic injection of targeted exosomes. Nat Biotechnol. 2011;29(4):341-345. doi:10.1038/nbt.1807

42. Ohno S, Takanashi M, Sudo K, et al. Systemically injected exosomes targeted to EGFR deliver antitumor microRNA to breast cancer cells. Mol Ther. 2013;21(1):185-191. doi:10.1038/mt.2012.180

43. Zeelenberg IS, Ostrowski M, Krumeich S, et al. Targeting tumor antigens to secreted membrane vesicles in vivo induces efficient antitumor immune responses. Cancer Res. 2008;68(4):1228-1235. doi:10.1158/0008-5472.CAN-07-3163

44. Hartman ZC, Wei J, Glass OK, et al. Increasing vaccine potency through exosome antigen targeting. Vaccine. 2011;29(50):9361-9367. doi:10.1016/j.vaccine.2011.09.133

45. Longatti A, Schindler C, Collinson A, et al. High affinity single-chain variable fragments are specific and versatile targeting motifs for extracellular vesicles. Nanoscale. 2018;10(29):14230-14244. doi:10.1039/C8NR03970D

46. Wang JH, Forterre AV, Zhao J, et al. Anti-HER2 scFv-directed extracellular vesicle-mediated mRNA-based gene delivery inhibits growth of HER2-positive human breast tumor xenografts by prodrug activation. Mol Cancer Ther. 2018;17(5):1133-1142. doi:10.1158/ 1535-7163.MCT-17-0827

47. Bao $\mathrm{H}, \mathrm{Bi} \mathrm{C}, \mathrm{Li} \mathrm{W}$, et al. Chimeric antigen receptor-engineered exosome as a drug delivery system in mantle cell lymphoma. Blood. 2017;130(Suppl. 1):5561.
International Journal of Nanomedicine

\section{Publish your work in this journal}

The International Journal of Nanomedicine is an international, peerreviewed journal focusing on the application of nanotechnology in diagnostics, therapeutics, and drug delivery systems throughout the biomedical field. This journal is indexed on PubMed Central, MedLine, CAS, SciSearch ${ }^{\mathbb{B}}$, Current Contents ${ }^{\mathbb{B}} /$ Clinical Medicine, $^{2}$
Journal Citation Reports/Science Edition, EMBase, Scopus and the Elsevier Bibliographic databases. The manuscript management system is completely online and includes a very quick and fair peer-review system, which is all easy to use. Visit http://www.dovepress.com/ testimonials.php to read real quotes from published authors. 